\title{
Euler Tours a través del software Scratch: una secuencia de tareas de investigación
}

\author{
Priscilla Frida Salles Tojeiro ${ }^{1}$ \\ priscillatojeiro@yahoo.com.br \\ https://orcid.org/0000-0001-5113-092X \\ Eliane Maria de Oliveira Araman'1 \\ eliane.araman@gmail.com \\ https://orcid.org/0000-0002-1808-2599 \\ ${ }^{1}$ Universidade Tecnológica Federal do Paraná (UTFPR, Brasil)
}

Recibido: 14/05/2020 Aceptado: 06/07/2020

\begin{abstract}
Resumen
El estudio presente tiene como objetivo presentar una secuencia de tareas, desarrolladas por los investigadores, así como los resultados de su aplicación para estudiantes de cuarto y quinto año de escuela primaria de una escuela en la ciudad de Ourinhos, Brasil. Inspirada en el problema histórico "Los siete puentes de Königsberg", que fue resuelto por Leonhard Euler dando lugar a la teoría de grafos, la secuencia comprende nueve tareas que se desarrollaron con el software Scratch. Al intentar resolver las tareas, los estudiantes lo hicieron de manera investigativa. La elección de este problema se caracterizó por su fácil contextualización con la realidad y al estar adaptada al contexto de los niños, permitió a los estudiantes percibir un uso práctico de los conocimientos aprendidos en el aula, tales como: mover objetos en el espacio plano, estudiar de vértices, aristas, números pares e impares, conocimiento esperado para los primeros años de la escuela primaria. La metodología adoptada fue de naturaleza cualitativa. Los resultados mostraron que los estudiantes pudieron acercarse a los cuatro teoremas ${ }^{1}$, que iniciaron la teoría de grafos. Las tareas les permitieron expresarse oralmente y por escrito, lo que permitió reflexionar sobre el objeto de estudio de estudiantes e investigadores.
\end{abstract}

Palabras clave: Nociones de Topología; Primeros años de la Escuela Primaria; Investigación Matemática; Scratch software.

\section{Passeios de Euler por meio do software Scratch: uma sequência de tarefas investigativas}

\section{Resumo}

O presente estudo tem como objetivo apresentar uma sequência de tarefas que foi desenvolvida pelas pesquisadoras bem como os resultados da aplicação desta para alunos do quarto e quinto ano do Ensino Fundamental de uma escola municipal na cidade de Ourinhos, Brasil. Inspirada no problema histórico "As sete pontes de Königsberg", que foi solucionado por Leonhard Euler dando origem a Teoria dos Grafos, a sequência compreende nove tarefas que foram desenvolvidas com o software Scratch. Ao tentarem resolver as tarefas, os alunos a fizeram de forma investigativa. A escolha por este problema caracterizou-se pela fácil contextualização com a realidade e ao ser adaptado ao contexto infantil, permitiu que os alunos percebessem uma utilização prática de conhecimentos aprendidos em sala de aula como: movimentação de objeto no espaço plano, estudo de 
vértices, arestas, números pares e ímpares, conhecimentos previstos como conteúdos dos Anos Iniciais do Ensino Fundamental. A metodologia adotada foi de natureza qualitativa. Os resultamos mostraram que os alunos conseguiram se aproximar dos quatro teoremas ${ }^{1}$, que deram início a Teoria dos Grafos. As tarefas permitiram que se expressassem oralmente e por meio de escrita, o que possibilitou reflexões sobre o objeto de estudo por parte dos alunos e das pesquisadoras.

Palavras-chave: Noções de Topologia; Anos Iniciais do Ensino Fundamental; Investigação Matemática; Software Scratch.

\title{
Euler Tours through the Scratch software: a sequence of investigative tasks
}

\begin{abstract}
The present study aims to present a sequence of tasks, developed by the researchers as well as the results of its application for students of the 4th and 5th year of Elementary School of a school in the city of Ourinhos, Brazil. Inspired by the historical problem "The seven Königsberg bridges", which was solved by Leonhard Euler giving rise to Theory of Graphs, the sequence comprises nine tasks that were developed with the Scratch software. When trying to solve the tasks, the students did it in an investigative way. The choice for this problem was characterized by its easy contextualization with reality and being adapted to the children's context, allowed students to perceive a practical use of knowledge learned in the classroom, such as: moving objects in the flat space, studying vertices, edges, even and odd numbers, knowledge expected for the Elementary School. The adopted methodology was of a qualitative nature. The results showed that the students were able to approached the four theorems ${ }^{1}$, which started the Graph Theory. The tasks allowed them to express themselves orally and through writing, which enabled reflections on the object of study by students and researchers.
\end{abstract}

Keywords: Notions of Topology; Elementary School; Mathematical Research; Scratch software.

\section{Introdução}

O ensino de Matemática para os Anos Iniciais, segundo Brasil (2017), tem como foco as práticas sociais, de forma que os estudantes devem manusear e utilizar os textos que circulam na sociedade para problematizações, integrando a Matemática dessa forma com as tecnologias e diversas áreas do saber. Neste sentido, o ensino concebido como

\footnotetext{
1 Teorema 1- Se um grafo planar admite um passeio de Euler, começando e terminando em um mesmo vértice, então todo vértice desse grafo tem ordem par. Teorema 2- Se um grafo planar admite um passeio de Euler, começando num vértice e terminando em outro, então os vértices final e inicial do passeio são ímpares, e todos os demais vértices do grafo têm ordem par. Teorema 3- Se um grafo tem seus vértices todos pares, então ele admite um passeio de Euler. Além disso, esse passeio pode começar (e terminar) em qualquer vértice previamente escolhido. Teorema 4- Se um grafo tem dois vértices ímpares e os demais todos pares, então ele admite um passeio de Euler. Esse passeio deve começar em um dos vértices ímpares e terminar no outro (Sampaio, 2010, p.12).
} 
apropriação cultural não pode se manter as margens da evolução tecnológica, principalmente por se tratar de instrumentos que os alunos gostam de manusear.

O uso de tecnologias associado à disciplina Matemática tem se mostrado cada vez mais crescente no Brasil, descritos nas pesquisas de Kalinke, Mocrosky e Estephan (2013) que, no ano de 2010, realizaram um levantamento na base de dados do Conselho Nacional de Desenvolvimento Científico - CNPQ em busca de pesquisadores que desenvolvem estudos utilizando algum recurso tecnológico associado ao ensino de Matemática, em que,

segundo dados da Plataforma Lattes, estes pesquisadores somados orientaram, nos últimos doze anos, 85 trabalhos de Mestrado e 25 de Doutorado, além de terem participado, neste mesmo período, de 229 bancas de Mestrado e 93 de Doutorado. (...) Houve mais de 250 defesas de Mestrados e Doutorados em 12 anos, o que representa mais de 20 defesas por ano. (p. 375)

E estes números tendem a crescer a cada ano, no entanto, percebe-se que na escola ainda vivenciam-se poucas experiências pedagógicas que utilizam esses recursos tecnológicos, principalmente nos Anos Iniciais do Ensino Fundamental.

No levantamento realizado pelas pesquisadoras em trabalhos apresentados nas XI, XII e XIII edições do EPREM ${ }^{2}$, Encontro Paranaense de Educação Matemática, que ocorreram respectivamente nos anos de 2011, 2014 e 2015, observou-se que foram apresentados nas categorias Comunicação Científica, Relato de Experiência e Pôster, um total de trezentos e sessenta e seis trabalhos, destes, foram selecionados quarenta e um que abordaram estudos relacionados aos Anos Iniciais o que representou pouco mais de onze porcento. Nenhum destes trabalhos contemplou o uso de Tecnologias para os Anos Iniciais do Ensino Fundamental (Tojeiro \& Araman, 2017).

Desta forma, tomando por pressuposto que as crianças gostam e apresentam grande facilidade em manusear estes recursos, e que cada vez mais estes poderão ser encontrados para uso didático, a sequência de atividades proposta utiliza recursos tecnológicos visando ampliar as possibilidades educativas, promover situações de aprendizagens que possam conduzir os alunos a perceberem a Matemática em seu cotidiano, bem como instigar seu espírito investigativo.

Mendes (2009), afirma que o ensino de Matemática aliada à investigação caracteriza-se em "importante ferramenta que conduz o ensino desta disciplina a uma

\footnotetext{
${ }^{2}$ Optou-se por realizar o levantamento de pesquisas no evento EPREM, uma vez que a pesquisa realizada foi desenvolvida no âmbito de um Programa de Pós-Graduação vinculado à Universidade Tecnológica Federal do Paraná, UTFPR.
} 
perspectiva sociocultural e construtivista, que permite uma visão geral da Matemática e sua aplicação prática por meio da interdisciplinaridade" (p. 19).

O ensino de Matemática sob esta perspectiva tende a um ensino mais eficaz, uma vez que envolve o estudante, permitindo-lhe uma visão holística em relação a sua aprendizagem e à Matemática. O presente estudo apresenta uma proposta de ensino de noções introdutórias de Topologia para alunos que frequentam os Anos Iniciais do Ensino Fundamental por meio de tarefas investigativas utilizando o software Scratch.

\section{Referenciais teóricos}

Tomou-se por referências teóricas neste estudo as pesquisas de Piaget (1975), Piaget e Inhelder (1993), e Sampaio (2010) uma vez que estas abordam as noções espaciais iniciais das crianças que são de origem topológica. Neste sentido, entendeu-se a necessidade de explicar estes conceitos topológicos uma vez que as tarefas apresentadas neste estudo são topológicas.

Diferentemente da geometria euclidiana, a Topologia compreende um ramo da Geometria que estuda as características qualitativas, não se importando com medidas de distâncias, ângulos, dimensões, entre outros. A Topologia pode ser considerada uma "Geometria da borracha" porque estuda as características que não se alteram quando uma forma sofre uma deformação, mantendo relações de equivalência com a forma original. Desta maneira, quando um triângulo se transforma em um quadrado ou em um círculo, os elementos que estavam no interior do triângulo devem permanecer no interior do quadrado ou círculo, os elementos que se encontravam vizinhos uns dos outros devem permanecer desta forma nas figuras transformadas (Rissi \& Franco, 2008). Essas características topológicas que são qualitativas fazem parte das primeiras noções espaciais infantis.

Segundo Piaget (1975), Lorenzato (2008) e Smole, Diniz e Cândido (2014) essas noções surgem no início da infância, quando a criança percebe as pessoas, os objetos e tudo ao seu redor. Com seu crescimento e experiências, passa a se relacionar com eles sem se perceber parte deste espaço o que ocorre apenas com mais maturidade. Neste sentido, a construção espacial da criança ocorre por meio de seu desenvolvimento intelectual, associado às suas relações com as pessoas e experiências manipulativas com os objetos de seu cotidiano, em que necessita agir, pegar, comparar, compor e decompor. Estas experiências proporcionam-lhe condições de representar os objetos, mesmo que estes não 
estejam em seu campo de visão, tornando-se capaz de representá-los de forma abstrata, apenas com o pensamento ao lembrar-se delas.

Segundo Piaget e Inhelder, estas características espaciais, são topológicas e qualitativas e compreendem as noções de:

- Vizinhança, explicada pela proximidade dos elementos percebidos em um mesmo campo;

- Separação, dois elementos vizinhos podem se interpenetrar e se confundir em parte: introduzir entre eles uma relação de separação consiste em dissociá-los;

- Ordem, que compreende a ordenação de objetos no espaço e pode apresentar configuração linear ou cíclica;

- Envolvimento, esta característica envolve três dimensões: quando se refere a um elemento de uma dimensão, esta relação se dá na forma de um entre dois. Com elemento bidimensional, esta relação se dá por meio de conceitos como interior/exterior (elementos dentro e fora de um círculo, por exemplo), quando se refere a elementos tridimensionais, a relação se estabelece por meio de conceitos como interioridade/exterioridade (interno/externo a uma caixa);

- Continuidade é perceber a continuidade do objeto quando este não se encontra em seu campo de visão, por exemplo, o seccionamento de uma figura ou linha até o seu último limite, conceito de infinito. (1993)

- Fronteira, "é a linha ou aresta que limita dois territórios ou duas faces" (Sampaio, 2004, p. 10).

Segundo Sampaio (2004), "um mapa é um grafo plano, cujas faces têm fronteiras que são caminhos simples fechados do grafo. Em um mapa, cada aresta é compartilhada por exatamente duas faces" (p.10).

Utilizou-se para a elaboração das tarefas a plataforma Scratch por ser de código aberto. Entende-se que o uso do Scratch, um recurso tecnológico no ensino de Matemática permite experiências de aprendizagem por meio de simulações, formulação e exploração de conjecturas, indo ao encontro dos preceitos da Investigação Matemática.

O uso do software Scratch caracteriza-se em recurso tecnológico com potencial para o ensino de Matemática pois possibilita a visualização, exploração e experimentação 
por parte dos alunos na compreensão dos conceitos estudados além de proporcionar a ludicidade em ambientes que já estão habituados como celulares e computadores. É uma plataforma de desenvolvimento de jogos e animações de livre acesso na internet. Segundo informações disponíveis no Scratch Foundation (2015), a plataforma foi desenvolvida em 2007 no Massachusetts Institute of Technology (MIT) para o ensino de programação e lógica computacional para crianças e adolescentes.

É possível desenvolver programas diretamente na plataforma online ou com o software instalado no computador. É multiplataforma, passível de instalação em sistemas operacionais como Windows, Linux e Mac.

Possui uma interface de programação amigável e intuitiva em forma de blocos lógicos coloridos. Por meio desta plataforma é possível desenvolver a programação, reutilizar partes de códigos já desenvolvidos por outros, bem como compartilhar suas criações no endereço eletrônico disponível para esta finalidade. É um recurso que permite a criação de inúmeras tarefas tanto por parte do professor quanto dos próprios alunos. As tarefas desenvolvidas permitem a investigação por parte dos alunos em uma proposta que os permite realizar simulações, que são

modelos dinâmicos e simplificados do mundo real. Estes modelos permitem a exploração de situações fictícias, de situações com risco, como manipulação de substância química ou objetos perigosos; de experimentos que são muito complicados, caros ou que levam muito tempo para se processarem, como crescimento de plantas; e de situações impossíveis de serem obtidas, como um desastre ecológico, [...] oferece a possibilidade do aluno desenvolver hipóteses, testá-las, analisar resultados e refinar os conceitos. Esta modalidade de uso do computador na educação é muito útil para trabalho em grupo, principalmente os programas que envolvem decisões. Os diferentes grupos podem testar diferentes hipóteses, e assim, ter um contato mais "real" com os conceitos envolvidos no problema em estudo. (Valente, 1993, p. 11)

Na proposta de ensino utilizando o software Scratch, as tarefas foram desenvolvidas pelas pesquisadoras, de forma que os alunos utilizaram a ferramenta para realizar as tarefas e investigações por meio de simulações, tentativas e análise dos erros.

Quanto a abordagem investigativa o estudo seguiu a concepção de Ponte, Brocardo e Oliveira (2013), que definem as questões investigativas de forma que, investigar "é descobrir relações entre objetos matemáticos conhecidos ou desconhecidos, procurando identificar as respectivas propriedades" (p. 13). 
É a busca por respostas para algum problema interessante, mobilizar e aplicar conhecimentos, elaborar hipóteses, testá-las. Desta forma, tarefas investigativas apresentam características,

cujo potencial é de despertar a curiosidade, à medida que os alunos se inserem na teorização e trazem elementos novos, ainda não considerados nas aulas ou na própria perspectiva do professor. Uma das finalidades dessas metodologias investigativas é a promoção da autonomia dos estudantes em sala de aula e fora dela, para que aprendam a lidar de modo pessoal com materiais, situações desafiadoras e ideias diversas e para que aprendam a questionar os objetos de conhecimento, a reformular o conhecimento já existente e experimentar novas maneiras de compreender, explicar e discutir suas ideias. Essas metodologias baseiam-se em princípios e estratégias de ensino e busca de aprendizagens por meio de métodos interrogativos, indagativos e problematizadores, que se fundamentam em um ensino pensado como um processo de educação progressiva que pressupõe a autoformação do aprendente e o desenvolvimento de um ensino global por parte do professor. (Mendes, 2018, p. 72)

Segundo Ponte, Brocardo e Oliveira (2013) são três momentos principais que devem ser observados em uma investigação Matemática, a saber :

1- Introdução da tarefa em que o professor faz a proposta à turma, pode ser oralmente ou por escrito;

2- Realização da investigação, que pode ser individual, em duplas ou coletivamente;

3- Discussão dos resultados, em que os alunos relatam aos colegas o trabalho realizado. (Ponte, Brocardo \& Oliveira, 2013, p. 25).

A introdução da tarefa investigativa é importante pois é neste momento que o professor apresenta a situação a ser investigada atentando-se para que todos compreendam a proposta. Ao propor a tarefa pode fazê-lo, de forma que os estudantes sintam-se motivados para a realização.

Em seguida, ele acompanha as investigações dos estudantes propondo boas perguntas para mantê-los envolvidos, esclarece alguns pontos, faz intervenções de maneira adequada, em momentos estratégicos, conduzindo-os aos seus próprios questionamentos, levando-os a acreditar que são capazes de buscar respostas. Nesta etapa, o professor disponibiliza um tempo para que os estudantes compartilhem suas ideias e efetuem debates, os estudantes poderão levantar algumas hipóteses, testá-las e discutir com seus colegas.

No terceiro momento da tarefa investigativa, os estudantes apresentam suas descobertas para o grande grupo, socializam seu trabalho. Nesta etapa, o professor pode ajudar e "garantir que sejam comunicados os resultados e os processos mais significativos da investigação realizada e estimular os alunos a questionarem-se mutuamente" (Ponte, 
Brocardo \& Oliveira, 2013, p. 41). Após esta discussão o professor sistematiza o conhecimento produzido pelos grupos, e neste sentido, pode esclarecer alguns pontos que eventualmente tenham ficado em aberto. $\mathrm{O}$ trabalho com tarefas investigativas podem conduzir os estudantes a vivenciarem a Matemática bem como enxergar sua função social no cotidiano. O processo investigativo pode se tornar mais rico e empolgante que o próprio resultado final, ou a solução do problema proposto pelo professor.

Pensando em uma forma de contribuir para o ensino de Matemática, este trabalho tem como objetivo apresentar uma sequência de nove tarefas que abordam noções introdutórias de geometria não euclidiana, no caso a Topologia, e que foram desenvolvidas com o software Scratch em uma perspectiva investigativa.

\section{Aspectos metodológicos adotados}

A metodologia utilizada foi a abordagem qualitativa uma vez que ela reflete o conhecimento empírico do pesquisador. As pesquisas qualitativas "tentam compreender os fenômenos pela ótica do sujeito. Neste sentido, têm como premissa que nem tudo é quantificável e que a relação que a pessoa estabelece com o meio é única e, portanto, demanda uma análise profunda e individualizada" (Malheiros, 2011, p. 31).

\section{Participantes e contexto}

As tarefas desenvolvidas foram aplicadas para quarenta e dois alunos de quarto e quinto ano de uma escola municipal da cidade de Ourinhos, (São Paulo, Brasil). Um dos alunos necessitava de atendimento educacional especializado, de forma que uma professora o acompanhou durante as tarefas. Estas, foram aplicadas durante as aulas de informática, que ocorrem uma vez por semana e fazem parte da matriz curricular. As tarefas foram aplicadas no período de 5 semanas.

Os resultados apresentam a forma com que os alunos se aproximaram dos teoremas desenvolvidos por Leonhard Euler a partir do uso da tecnologia. O professor de Informática destes estudantes e a professora de atendimento educacional especializado colaboraram com a aplicação das atividades apenas como suportes tecnológico e pedagógico, respectivamente.

De acordo com os objetivos do estudo, foram utilizadas algumas técnicas como, observação dos estudantes ao realizarem as tarefas e as discussões com seus colegas, 
fotografias destes realizando as tarefas, respondendo aos questionamentos das fichas de trabalho e discutindo com seus pares, gravações de áudios e vídeos sobre seus argumentos e realização das atividades, anotações em diário de bordo quanto às dúvidas que surgiram e como foram orientados, bem como as fichas de trabalho das atividades preenchidas pelos alunos.

O termo tarefa, utilizado neste estudo remete ao trabalho a ser realizado pelos alunos e foi entendido na concepção de Ponte (2005) em que esta caracteriza-se no objetivo da atividade e pode se apresentar de várias formas dependendo do conhecimento que o aluno dispõe para solucionar cada um. No caso das tarefas de investigação, estas "promovem o envolvimento dos alunos, pois requerem a sua participação ativa desde a primeira fase do processo" (Ponte, 2005, p.7).

\section{Apresentação das tarefas Passeios de Euler}

A sequência consiste em nove tarefas, as oito primeiras são realizadas no software Scratch em que o aluno movimenta um personagem (gato) que deve percorrer cada uma das arestas do grafo passando por elas apenas uma única vez, na tentativa de realizar um passeio, chamado de Passeio de Euler. Durante estas tarefas, os alunos respondem a uma ficha de trabalho com questões que lhe chamam a atenção para pontos estratégicos a serem observados como: a quantidade de vértices ímpares em um determinado grafo, a partir de qual vértice do grafo é possível realizar o passeio, entre outras. A nona tarefa consiste em realizar análises nas fichas de trabalhos das oito tarefas anteriores, discutir com os pares e responder a uma nova ficha de trabalho na tentativa de se aproximar de um teorema matemático. As fichas de trabalho encontram-se associadas às tarefas a que se referem e podem ser acessadas na plataforma Scratch cujos links encontram-se em notas de rodapé.

Durante esta sequência de tarefas os alunos perpassam pelas três etapas de uma investigação matemática na concepção de Ponte, Brocardo e Oliveira (2013).

Um passeio de Euler consiste em percorrer cada uma das arestas de um grafo passando por todas elas apenas uma vez (Sampaio, 2010). O problema que inspirou as tarefas consistia na travessia pelas pontes de uma cidade, descrito a seguir.

O rio Pregel separa a cidade de Königsberg em quatro partes, e estas são interligadas por sete pontes. Os moradores desafiavam os visitantes a realizarem um passeio pelas quatro partes da cidade de forma que passassem apenas uma vez por cada 
uma das sete pontes. Euler desvenda o mistério, comprovando que o passeio é impossível, dando origem à Teoria dos Grafos. Ao estudar o mapa de Königsberg percebeu que deveria analisar as conexões permitidas pelas pontes nas distintas partes da cidade e que as distâncias envolvidas eram irrelevantes, desta forma, transformou o mapa em um grafo, composto por linhas e pontos. Percebeu então que, para que o passeio fosse possível, ele deveria percorrer as linhas com um lápis sem tirá-lo do papel, passando apenas uma vez por cada linha, caracterizando-se no que mais tarde foi chamado de "Passeio de Euler" (Sampaio, 2010).

\section{Tarefas implementadas com o software}

Ao iniciar a sequência de tarefas com os alunos, conceitos como vértices, arestas, números pares e ímpares foram retomados e foi introduzido o conceito de grafo. Em seguida, foram exibidas duas animações em Scratch, a primeira intitulada de Apresentação $^{3}$, que apresenta o problema das Sete Pontes de Königsberg, para contextualizar e incentivá-los a realizar as tarefas, e a segunda animação Orientações ${ }^{4}$, com as orientações sobre os comandos a serem utilizados durante as tarefas com o software Scratch.

Neste momento introdutório, perpassa-se pela primeira etapa da Investigação Matemática, descrita por Ponte, Brocardo e Oliveira (2013, p. 25) "(i) introdução da tarefa, em que o professor faz a proposta à turma, oralmente ou por escrito".

As oito primeiras tarefas de investigação foram mediadas por uma tecnologia digital, no caso o software Scratch, a nona tarefa consiste em retomar os estudos e fichas de trabalho das oito atividades para que juntos elaborem suas conjecturas e possam se aproximar dos teoremas. Durante as nove tarefas investigativas os alunos vivenciam a segunda etapa da Investigação. Segundo Ponte, Brocardo e Oliveira (2013) é nesta etapa que os alunos avançam para a "(ii) realização da investigação, individualmente, aos pares, em pequenos grupos ou com toda a turma.” (p.25). As tarefas serão descritas em seguida, bem como a qual teorema podem se aproximar com a investigação e realização destas.

Na tarefa 1 (Figura 1), os alunos podem se aproximar do Teorema 1: "se um grafo planar admite um passeio de Euler, começando e terminando em um mesmo vértice, então todo vértice desse grafo tem ordem par" (Sampaio, 2010, p.12).

\footnotetext{
${ }^{3}$ Animação Apresentação: https://scratch.mit.edu/projects/244866900/

${ }^{4}$ Animação Orientações: https://scratch.mit.edu/projects/244868498/
} 
De qualquer vértice do grafo que se inicia o passeio, todas as arestas são percorridas uma única vez e o local de partida também é o de chegada.

Figura 1: Tarefa 1 - Retângulo ${ }^{5}$ e Tarefa 2 - Retângulo com Diagonal ${ }^{6}$

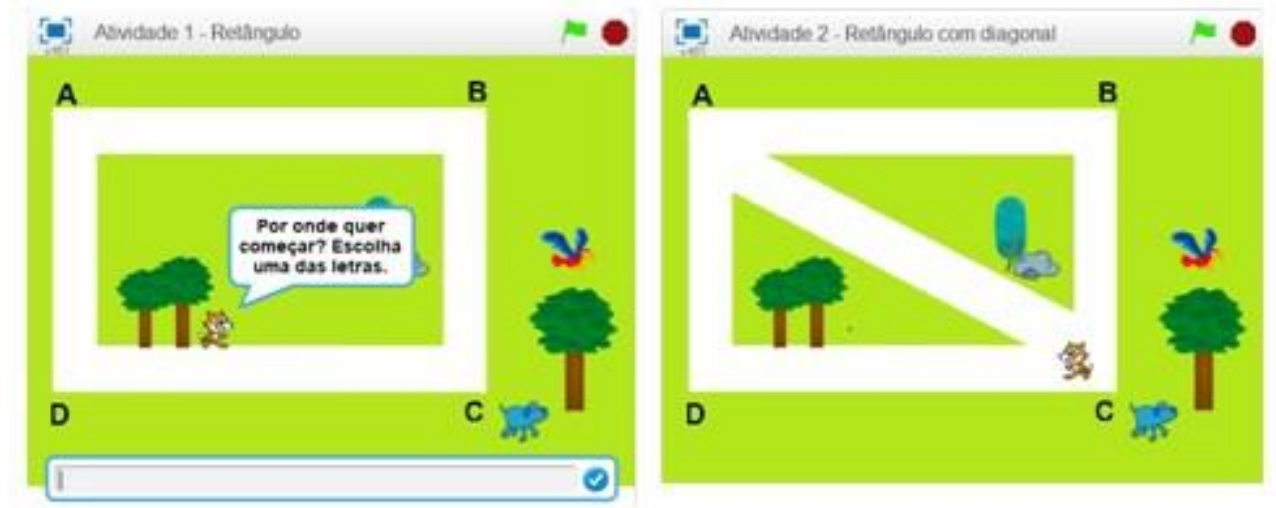

Fonte: Elaborado pelas autoras (2020)

Na tarefa 2 (Figura 1), os alunos podem se aproximar do Teorema 2: "se um grafo planar admite um passeio de Euler, começando num vértice e terminando em outro, então os vértices final e inicial do passeio são ímpares, e todos os demais vértices do grafo tem ordem par" (Sampaio, 2010, p.12).

Este grafo apresenta dois vértices de ordem par, B e D (com duas arestas) e dois de ordem ímpar A e C, (com três arestas). O passeio só é possível quando se parte de um dos vértices ímpares, e a chegada é sempre no outro vértice ímpar. Um grafo não pode ter mais do que dois vértices ímpares para que haja a possibilidade de se fazer um passeio de Euler por ele.

Na tarefa 3 (Figura 2), os alunos podem perceber características dos Teoremas 2 e 4. Teorema 4: "se um grafo tem dois vértices ímpares e os demais todos pares, então ele admite um passeio de Euler. Esse passeio deve começar em um dos vértices ímpares e terminar no outro" (Sampaio, 2010, p.12).

Assim como o grafo da tarefa 2, na tarefa 3 é possível fazer um passeio de Euler pois ele possui dois vértices ímpares e os demais pares. Por este grafo o passeio é possível a partir dos vértices B e C, com três arestas cada.

Na tarefa 4 (Figura 2), os alunos podem perceber características do Teorema 4, descrito anteriormente. Este é o primeiro grafo da sequência em que não é possível fazer um passeio de Euler.

\footnotetext{
5 Tarefa 1: https://scratch.mit.edu/projects/245070284/

6 Tarefa 2: https://scratch.mit.edu/projects/245077498/
} 
Figura 2: Tarefa 3 - Retângulo com Losango ${ }^{7}$ e Tarefa 4 - Retângulo com Losango e Diagonal ${ }^{8}$
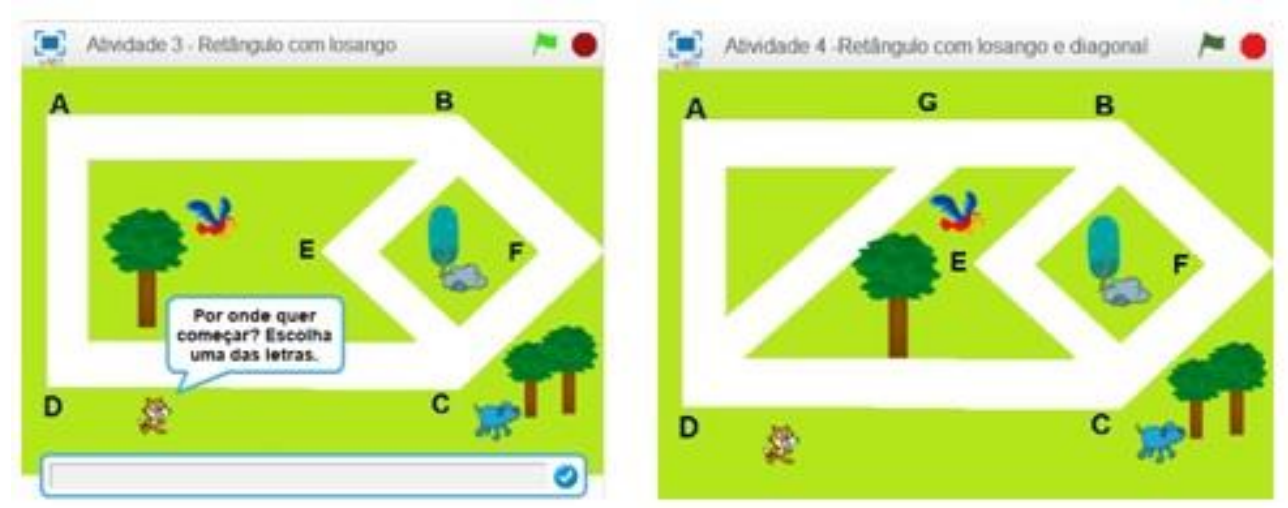

Fonte: Elaborado pelas autoras (2020)

Nos vértices B, C, D e G, encontram-se três semirretas cada, constituindo-se em vértices de ordem ímpar. Partindo-se de qualquer um dos vértices deste grafo, não se consegue realizar um Passeio de Euler. Na tarefa 5 (Figura 3), os alunos podem perceber características do Teorema 4. Por este grafo não é possível fazer o passeio de Euler, uma vez que possui quatro vértices ímpares (A, B, C e D).

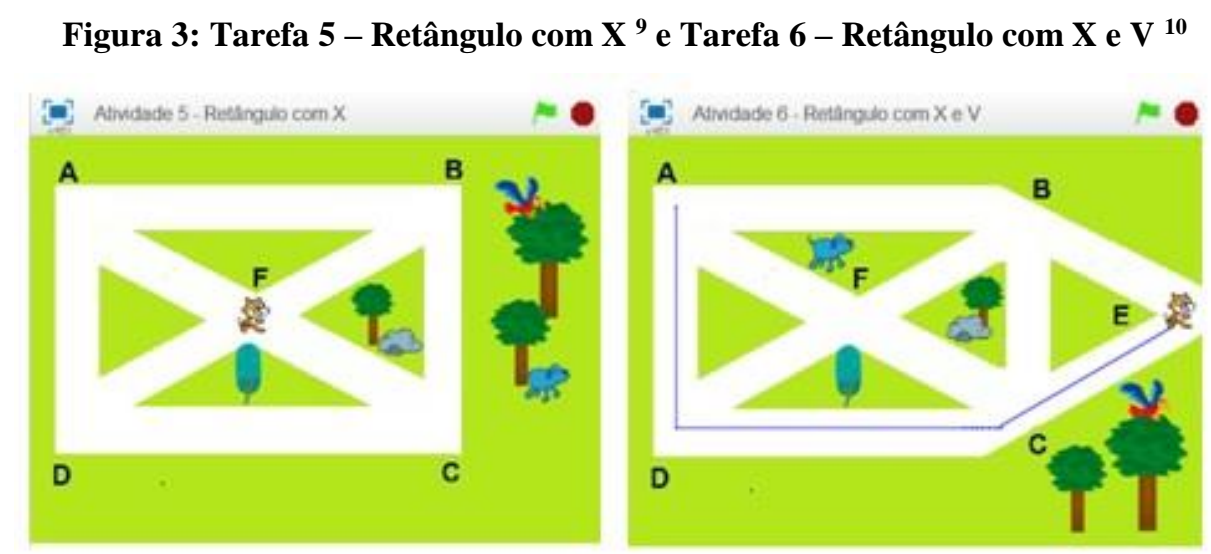

Fonte: Elaborado pelas autoras (2020)

$\mathrm{Na}$ tarefa 6 (Figura 3), é possível fazer o passeio de Euler apenas quando o personagem parte dos vértices $\mathrm{A}$ e $\mathrm{D}$, com três arestas cada. Os demais vértices são pares. Pretende-se com esta tarefa que os estudantes percebam características dos Teoremas 2 e 4.

\footnotetext{
${ }^{7}$ Tarefa 3: https://scratch.mit.edu/projects/245078780/

${ }^{8}$ Tarefa 4: https://scratch.mit.edu/projects/245077498/

${ }^{9}$ Tarefa 5: https://scratch.mit.edu/projects/245080522/

${ }^{10}$ Tarefa 6: https://scratch.mit.edu/projects/245084607/
} 


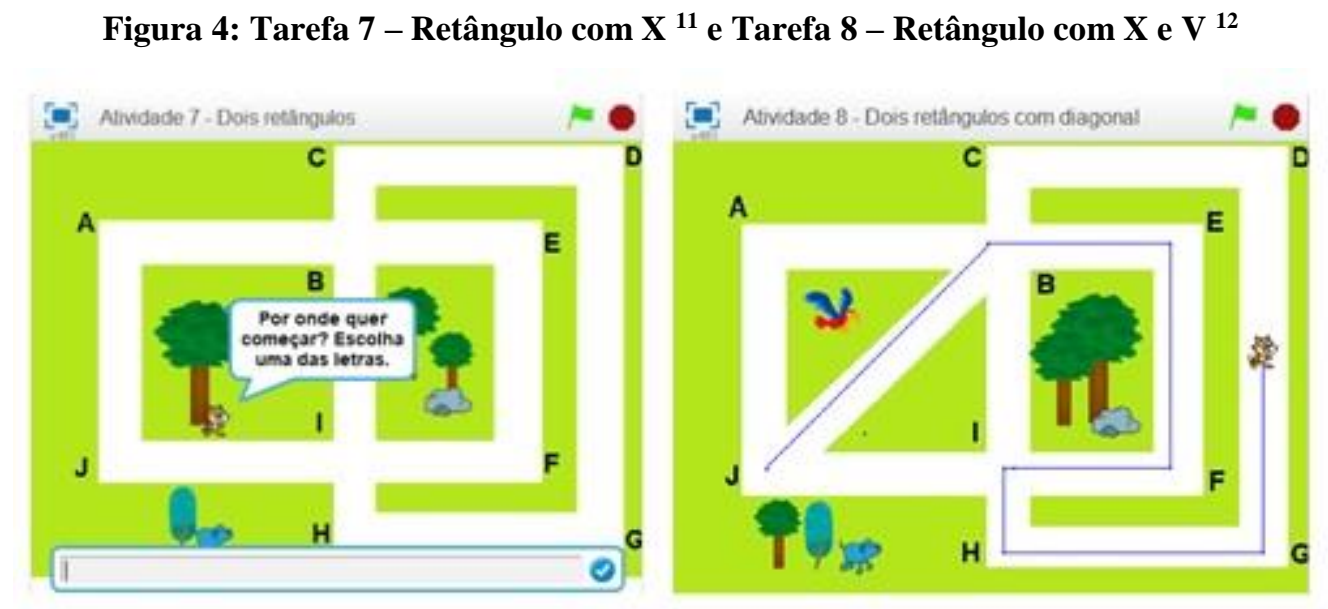

Fonte: Elaborado pelas autoras (2020)

Na tarefa 7 (Figura 4), é possível fazer um passeio de Euler. Todos os vértices são pares. O vértice de partida sempre é o mesmo de chegada. É possível que os estudantes se aproximem dos Teoremas 1 e 3 ao realizarem esta tarefa.

Teorema 3: Se um grafo tem seus vértices todos pares, então ele admite um passeio de Euler. Além disso, esse passeio pode começar (e terminar) em qualquer vértice previamente escolhido. O primeiro arco do caminho pode ser qualquer arco partindo desse vértice (Sampaio, 2010, p. 12).

Na tarefa 8 (Figura 4), é possível fazer um passeio de Euler pelo grafo que apresenta apenas dois vértices ímpares, B com cinco arestas e J com três. Quando o passeio se inicia em um destes vértices no outro se chega. Ao realizarem esta tarefa os alunos podem perceber características dos Teoremas 2 e 4 .

O propósito destas oito tarefas foi permitir que os alunos experimentassem suas hipóteses, fizessem as tarefas, refazendo-as quando necessário, experimentando o passeio a partir de diferentes vértices, que trocassem opiniões com seus pares e ao responderem aos questionamentos das fichas de trabalho, que são as folhas impressas, começassem a investigar o porquê de se conseguir realizar o Passeio de Euler por uns grafos e não por outros.

\section{Tarefa implementada sem o software}

$\mathrm{Na}$ tarefa 9 os alunos não utilizaram o Scratch, eles se reuniram em quatro grandes grupos com as fichas de trabalho respondidas nas oito tarefas anteriores para fazerem análises nestas e observar por quais grafos conseguiram realizar o passeio, o que estes

\footnotetext{
11 Tarefa 7: https://scratch.mit.edu/projects/245085831/

12 Tarefa 8: https://scratch.mit.edu/projects/245085989/
} 
grafos possuuiam de semelhantes, observaram as regularidades, investigaram e discutiram com seus pares.

Cada grupo recebeu uma nova ficha com questões a serem respondidas que se diferenciava das fichas dos demais grupos por que cada uma remetia a apenas um dos 4 teoremas. Seguem as fichas de trabalho da tarefa 9 de cada um dos quatro grupos com os questionamentos, em seguida apresentam-se as respostas elaboradas pelos alunos.

\section{$\underline{\text { Grupo } 1}$}

\section{Figura 5: Grafos e questionamentos do Grupo 1}

\begin{tabular}{|l|l|}
\hline Grafos & Questionamentos \\
\hline & $\begin{array}{l}\text { Foi possível fazer um Passeio de Euler por } \\
\text { todos estes grafos. } \\
\text { Responda: } \\
1-\text { Em quais destes grafos você começou o } \\
\text { passeio e terminou no mesmo vértice? } \\
2-0 \text { grafo possui apenas vértices com } \\
\text { arestas pares? } \\
\text { 3-Em quais destes grafos você começou o } \\
\text { passeio em um vértice e terminou em } \\
\text { outro? } \\
4-0 \text { grafo possui apenas vértices com } \\
\text { arestas ímpares? } \\
5-\text { O que podemos perceber? }\end{array}$ \\
\hline
\end{tabular}

Fonte: Elaborado pelas autoras (2020)

A ficha de trabalho do Grupo 1 apresentava quatro grafos em que o passeio foi possível. Por meio desta ficha esperava-se que se aproximassem do Teorema 1, (Figura 5).

\section{Grupo 2}

A ficha de trabalho do Grupo 2 continha quatro grafos que possuíam dois vértices ímpares e os demais pares cada um, de forma que o passeio em todos era possível. Por meio desta ficha esperava-se que se aproximassem do Teorema 2, (Figura 6). 
Figura 6: Grafos e questionamentos do Grupo 2

\begin{tabular}{|l|l|}
\hline Grafos & Questionamentos \\
\hline & $\begin{array}{l}\text { Por estes grafos foi possível fazer um } \\
\text { passeio de Euler. } \\
1 \text { - Nestes grafos você começou e terminou } \\
\text { opasseio no mesmo vértice? } \\
2 \text { - Estes grafos possuem apenas vértices } \\
\text { com números pares de arestas? } \\
3 \text { - Quantos vértices com arestas ímpares } \\
\text { esses grafos possuem? } \\
4-\text { Quais são os vértices com aresta } \\
\text { impares? } \\
5 \text {-O que você percebe aqui? }\end{array}$ \\
\hline
\end{tabular}

Fonte: Elaborado pelas autoras (2020)

\section{$\underline{\text { Grupo } 3}$}

A ficha de trabalho do Grupo 3 apresentava dois grafos e cada um possuía apenas vértices pares, de forma que o passeio é possível. Por meio desta ficha esperava-se que se aproximassem do Teorema 3, (Figura 7).

Figura 7: Grafos e questionamentos do Grupo 3

\begin{tabular}{|l|l|l|}
\hline Grafos & Questionamentos \\
\hline & $\begin{array}{l}\text { 1- Você pode fazer um passeio de Euler } \\
\text { por estes grafos? } \\
\text { 2-Se você começar o passeio no vértice B, } \\
\text { onde você vai terminar? } \\
\text { 3- Se você começar o passeio no vértice C, } \\
\text { ou em qualquer outro vértice, onde vai } \\
\text { terminar? } \\
4\end{array}$ \\
\hline
\end{tabular}

Fonte: Elaborado pelas autoras (2020)

\section{Grupo 4}

A ficha de trabalho do Grupo 4 apresentou dois grafos que possuíam quatro vértices ímpares em cada um, o passeio não é possível nestes grafos. Por meio desta ficha esperavase que se aproximassem do Teorema 4, (Figura 8). 
Figura 8: Grafos e questionamentos do Grupo 4

\begin{tabular}{|l|l|}
\hline Grafos & Questionamentos \\
\hline & $\begin{array}{l}\text { 1- Você pode fazer um passeio de Euler por } \\
\text { estes grafos? } \\
\text { 2- Quantos vértices com número ímpar de } \\
\text { arestas têm estes grafos? } \\
3 \text { - O que você percebe aqui? }\end{array}$ \\
\hline
\end{tabular}

Fonte: Elaborado pelas autoras

A terceira fase de uma Investigação Matemática na concepção dos autores estudados, Ponte, Brocardo e Oliveira (2013, p. 25), é a (iii) discussão dos resultados, em que os alunos relatam aos colegas o trabalho realizado".

Após as discussões, os alunos apresentaram suas conclusões para os colegas e pesquisadora/professora. Esta, desempenhou a função de mediadora, realizando questionamentos e esclarecendo algumas dúvidas que eventualmente os alunos tiveram finalizando com uma sistematização dos conhecimentos aprendidos.

\section{Produções dos alunos}

Os alunos que receberam a tarefa Grupo 1, deveriam se aproximar do Teorema 1. Após a análise das respostas dadas pelos alunos de quarto e quinto anos, percebeu-se que eles conseguiram se aproximar dos Teoremas 1 e 2 .

O Grupo 1 formado pelos alunos de quarto ano era composto por cinco participantes, a transcrição da resposta deles foi apresentada com correções ortográficas. "Percebemos: Quando os vértices são pares, terminam nos mesmos vértices e formam pares que conseguem formar grupos e terminar no mesmo caminho. Mas, quando o vértice é ímpar ele não pode terminar no mesmo vértice, mas ele pode completar o passeio".

O Grupo 1 formado pelos alunos de quinto ano era composto por cinco participantes, segue a transcrição da resposta deles: "quando você começa em uma aresta par, você termina em par. Quando começa em ímpar, termina em ímpar”.

Percebe-se pelas respostas que nenhuma das turmas conseguiu perceber que para que o passeio seja possível em grafos com vértices ímpares a quantidade destes precisa ser apenas dois. Contudo, percebe-se que os alunos do quarto ano aproximam-se melhor quando escreveram que em vértices pares o passeio "termina no mesmo vértice de partida", e que com vértices ímpares o passeio "não termina no mesmo vértice de partida". 
O Grupo 2 formado por alunos do quarto ano era composto por cinco participantes, é possível observar pela ficha de trabalho respondida por eles, Figura 9, que tiveram dificuldades em se aproximar do Teorema 2, talvez porque a ficha de trabalho continha muitas anotações que os atrapalhou.

Figura 9: Respostas do Grupo 2 formado por alunos do $4^{\circ}$ ano

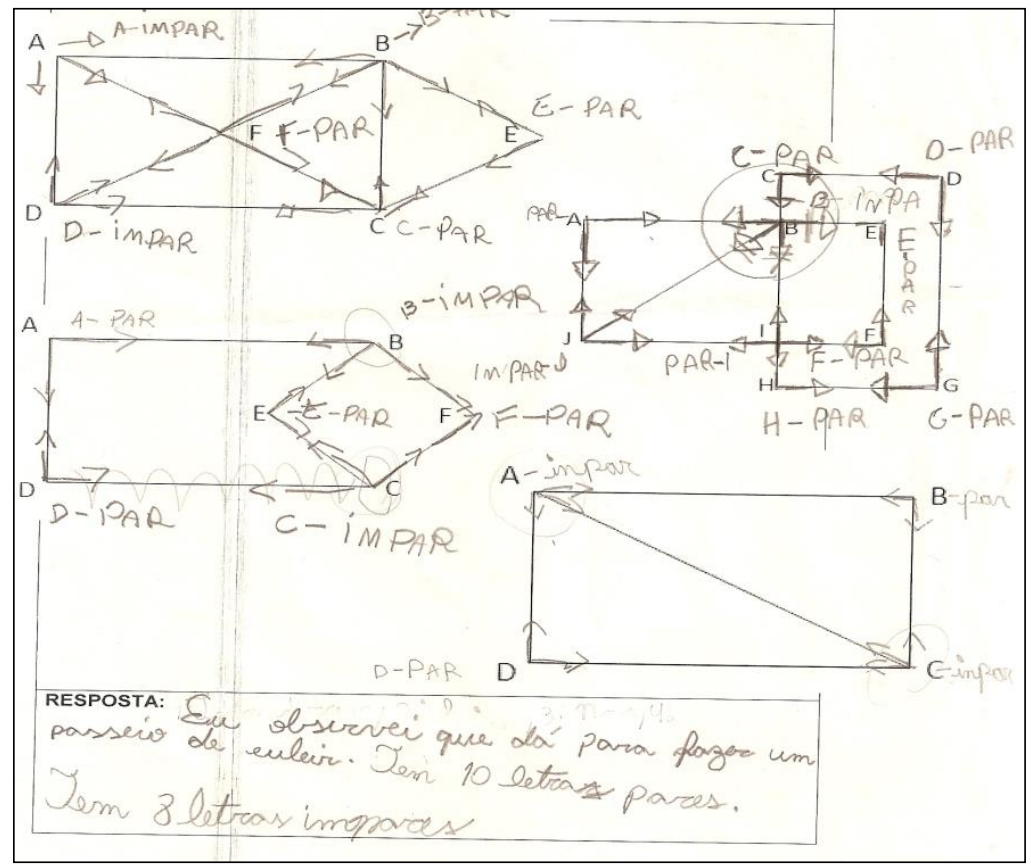

Fonte: A pesquisa (2020)

Entendeu-se a necessidade da transcrição do vídeo de apresentação deste grupo para ilustrar os questionamentos da pesquisadora e respostas do estudante, demonstrando que o grupo compreendeu melhor a atividade depois das intervenções.

Estudante: Nós descobrimos que todos com vértices ímpares terminam em vértice ímpar diferente.

Pesquisadora: Então nestes grafos, quantos vértices ímpares tem no primeiro desenho, lá em cima?

Estudante: Dois.

Pesquisadora: No debaixo.

Estudante: Dois [sempre olhando sua folha de respostas]

Pesquisadora: E nos outros dois lá, quantos vértices ímpares eles têm?

Estudante: Dois também.

Pesquisadora: Então, em todos aqueles grafos têm dois vértices impares, só dois?

Estudante: $E_{\text {. }}$

Pesquisadora: E o passeio começa onde, para dar certo?

Estudante: Em um vértice impar.

Pesquisadora: E termina onde?

Estudante: Em outro vértice impar.

Pesquisadora: Isso. 
Entretanto, não é possível afirmar se conseguiram perceber tal relação por si mesma, uma vez que a segunda resposta escrita, após os questionamentos da pesquisadora, não se aproximou adequadamente do teorema.

Esta resposta foi entregue no verso da folha de atividade, representado na Figura 10.

Figura 10: Respostas do Grupo 2 formado por alunos do $4^{\circ}$ ano - após intervenção

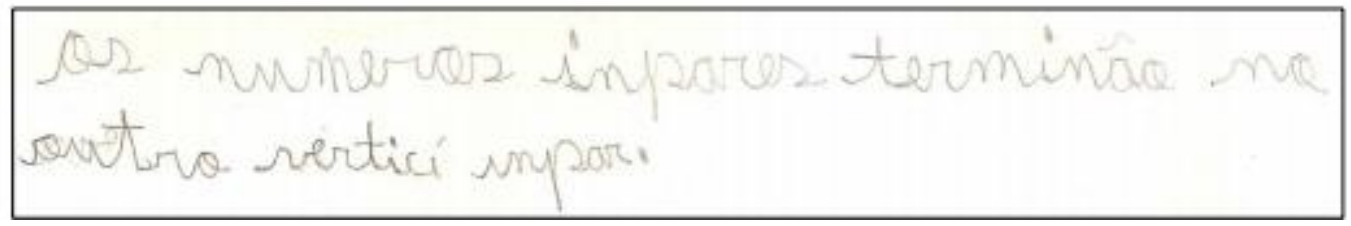

Fonte: A pesquisa (2020)

O Grupo 2 formado por alunos de quinto ano era composto por quatro participantes e foi possível observar que perceberam características do Teorema 2 e foram além, ao manusearem as fichas de trabalho das tarefas anteriores, perceberam que, se o grafo apresenta mais do que dois vértices ímpares o passeio não é possível. Na transcrição da resposta: "se tem dois ímpares no grafo você vai começar no vértice ímpar e vai terminar no vértice ímpar e se tiver três vértices ímpares você não vai conseguir fazer o Passeio de Euler".

Ao responderem aos questionamentos desta nova ficha, os grupos poderiam perceber características de todos os teoremas uma vez que já haviam realizados as 8 primeiras atividades.

O Grupo 3 dos alunos de quarto ano era composto por quatro estudantes. Este grupo conseguiu se aproximar do Teorema 3. Na transcrição da ficha perceberam: "todos são pares. Os dois grafos são os mesmos, só que um deles tem um em cima do outro. No primeiro você começa e termina no mesmo vértice, no segundo você começa em um e termina no mesmo".

Os alunos do Grupo 3 de quinto ano, formado por quatro participantes, também se aproximaram do Teorema 3, na transcrição: "a $n^{\circ} 1$ termina sempre na letra que começa. Na segunda também".

O Grupo 4 formado pelos alunos do quarto ano, era composto por quatro participantes. Eles perceberam que não era possível o passeio pelos grafos. Mediante intervenções da pesquisadora, responderam oralmente e não conseguiram transcrever para a folha de respostas. 
Figura 11: Respostas do Grupo 4 formado por alunos do $4^{\circ}$ ano

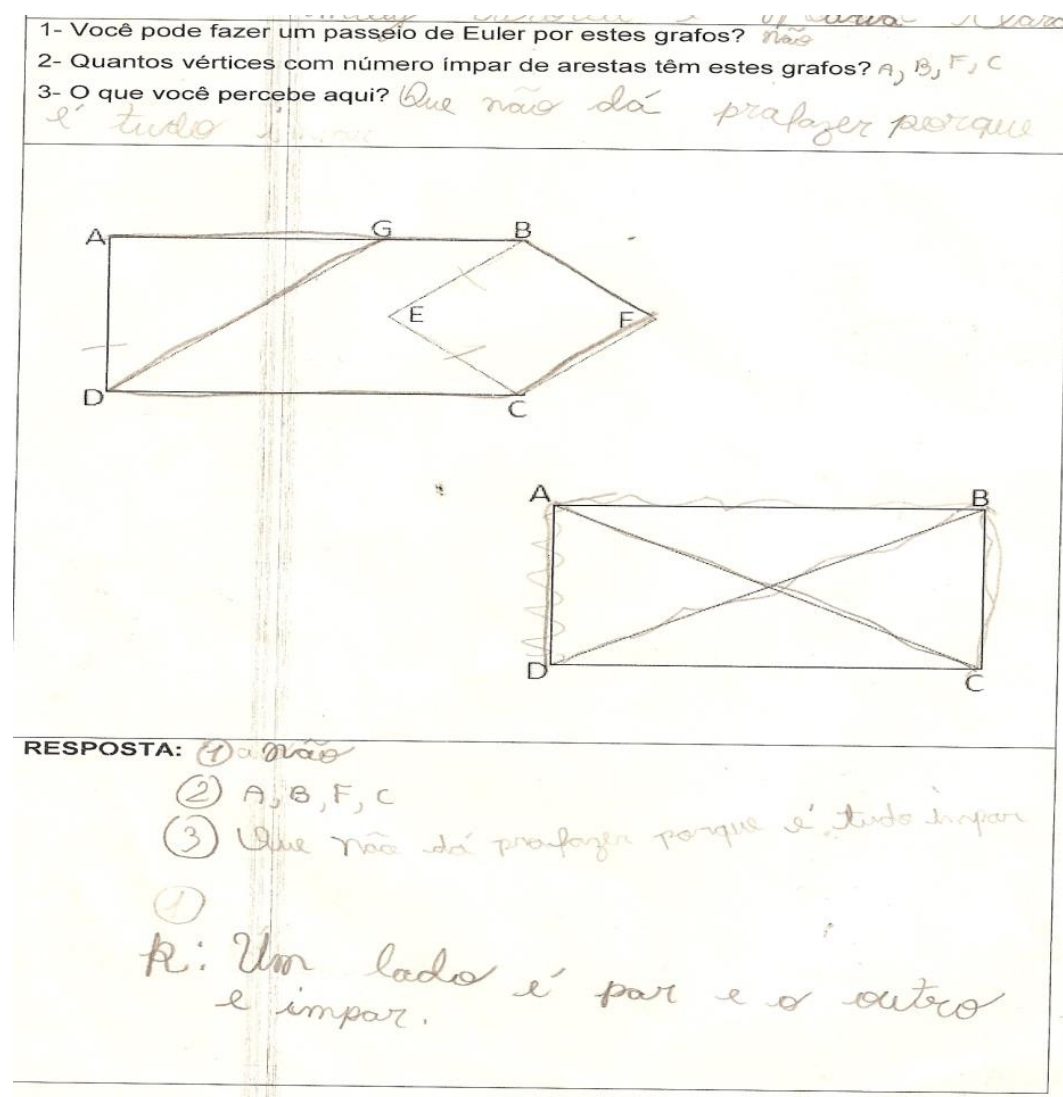

Fonte: A pesquisa (2020)

Quando se questionou quantos vértices ímpares os grafos apresentavam, eles responderam com as letras dos vértices e não com uma quantidade, como se esperava. E ainda assim, não responderam corretamente, pois os vértices B e C são ímpares e não pares como eles responderam, verificado na Figura 11.

O Grupo 4 formado pelos alunos de quinto ano era composto por quatro participantes. Parece, segundo a transcrição de suas respostas, não terem conseguido se aproximar do Teorema 4, “ nenhum dá porque tem mais ímpares do que pares.” O passeio não foi possível nestes grafos porque eles possuem mais do que dois vértices ímpares, a quantidade de vértices pares em grafos que apresentam dois vértices ímpares não é relevante.

Para cada grupo foi solicitado que percebessem características de um dos teoremas. Ao final da sequência, a pesquisadora retomou cada um dos teoremas estudados. Utilizando desenhos dos grafos feitos na lousa, explicou todas as possibilidades de se fazer um passeio de Euler por alguns grafos e não por outros.

Explicou que estes Teoremas estudados deram origem à Teoria dos Grafos, muito utilizado em diversas áreas como Matemática, Tecnologia, Logística, Inteligência Artificial, entre outros. 
Percebeu-se que a maior parte dos estudantes conseguiu se aproximar dos teoremas após a realização das tarefas e depois por meio das análises das fichas de trabalho.

\section{Considerações finais}

O presente estudo de cunho qualitativo apresentou uma sequência de tarefas em que buscou-se compreender como estudantes dos Anos Iniciais do Ensino Fundamental se aproximam das noções topológicas, em específico dos teoremas desenvolvidos por Leonhard Euler, por meio de tarefas investigativas utilizando o software Scratch.

Desta forma, as tarefas elaboradas neste estudo foram inspiradas no problema das Sete Pontes de Königsberg, que segundo Sampaio (2010), deu início à Teoria dos Grafos quando o matemático Leonhard Euler resolveu um problema proposto pelos moradores aos visitantes da cidade Königsberg, na antiga Prússia em 1736. Este problema histórico é de natureza topológica porque considera as informações qualitativas e não quantitativas.

Para o desenvolvimento das tarefas foram analisadas as concepções de autores relacionados à Investigação Matemática, uso de recursos tecnológicos para o ensino de Matemática e quanto ao ensino e desenvolvimento espacial na perspectiva topológica como noções de vizinhança, separação, ordem, envolvimento, continuidade e fronteira. Entendeu-se a necessidade de apresentar as noções espaciais descritas por Piaget (1975), Piaget e Inhelder (1993), Lorenzato (2008) e Smole, Diniz e Cândido (2014) por se tratarem de conhecimentos inerentes da infância e que caracterizam as atividades propostas. Tomando por pressuposto estes estudos de que os primeiros conhecimentos espaciais das crianças envolvem as noções topológicas, e que estes, se dão por meio de experiências manipulativas no objeto do conhecimento, associadas ao seu desenvolvimento cognitivo, as tarefas propostas tiveram a pretensão de contribuir com esta formação, quando propuseram um ensino em Geometria não-euclidiana, pouco explorado nos Anos Iniciais do Ensino Fundamental

A investigação Matemática na perspectiva de Ponte, Brocardo e Oliveira (2013) aliada ao uso da tecnologia mostrou-se uma metodologia de ensino com potencial para que os alunos aprendam matemática. Os estudantes puderam refazer os passeios diversas vezes com a finalidade de perceber regularidades, elaborar e validar suas conjecturas até se aproximarem dos teoremas que sustentam a Teoria dos Grafos. 
As respostas dos alunos nas fichas de trabalho indicaram que alguns estudantes apresentaram dúvidas quanto ao conceito de pares e ímpares associado aos vértices, fato que dificultou o entendimento de algumas tarefas. A pesquisadora realizou explicações pontuais sempre que esta dificuldade se verificava, orientando que refizessem as questões.

Outra questão em destaque foi a dificuldade que os alunos apresentaram para responder ao que se pedia nas perguntas. Quando se perguntava uma quantidade, como: “quantos são os vértices ímpares neste grafo?” alguns estudantes respondiam com o nome dos vértices, como: “A, B e C", o oposto também se verificou. Percebeu-se com este estudo que os alunos apresentaram dificuldades em compreender alguns enunciados de questões propostas.

O uso de recursos tecnológicos no ensino de Matemática tem se mostrado uma tendência, descritas nas pesquisas desenvolvidas por Kalinke, Mocrosky e Estephan (2013). Estes recursos permitem de forma rápida e precisa que se realizem testes de conjecturas, simulações e permitem que eventos sejam repetidos inúmeras vezes a partir de modificações em alguns parâmetros, muitas vezes de difícil execução quando realizados manualmente. Segundo Ponte, Quaresma, Mata-Pereira e Branco (2017),

o uso crescente de instrumentos tecnológicos na sala de aula, em especial o computador, é, provavelmente o principal fator responsável pela divulgação e crescente aceitação das tarefas de exploração e investigação. Na verdade, as tecnologias permitem simular com facilidade situações complexas que, de outro modo, teríamos dificuldade de estudar. Permitem verificar o que acontece num grande número de casos, favorecendo a formulação de testes de conjecturas (p.215).

A aplicação das tarefas utilizando o Scratch permitiu que os alunos testassem suas hipóteses diversas vezes na busca de regularidades, apagando-as e refazendo-as, não demonstrando dificuldades quanto ao uso deste. As tarefas se realizaram mais rápido, de forma eficaz e ainda com certa ludicidade, quantas vezes se fizessem necessárias. Se precisassem realizar manualmente, precisariam dispor de maior tempo e material.

Por meio das tarefas, tiveram a oportunidade de experimentar e conhecer o objeto do estudo de forma manipulativa no software Scratch e se aproximarem de características dos teoremas observando as regularidades encontradas, respondendo e comparando suas fichas de trabalho, o que foi observado em registros dos alunos. A formalização realizada pela pesquisadora e as discussões finais, tinham como objetivo possibilitar aos estudantes a percepção de que a Matemática é necessária para resolver problemas, dos mais simples aos mais complexos e que ela se constitui a partir de uma necessidade real e por meio do 
esforço de muitos. Tiveram a possibilidade de conhecer uma aplicação prática dos conceitos estudados como vértices, arestas, percursos e trajetos.

Tarefas como estas permitem que os alunos percebam que parte da responsabilidade do aprender é sua, pois precisam mobilizar outros conhecimentos para resolverem as questões propostas, trabalharem em equipe e persistirem na busca desempenhando um papel mais ativo na aprendizagem.

As tarefas investigativas propostas por meio do software Scratch, permitem que os alunos realizem os passeios pelos grafos quantas vezes sentirem necessidade para elaborarem suas conjecturas, discutirem suas percepções e se aproximarem dos Teoremas que fundamentam a Teoria dos Grafos.

\section{Referências}

Brasil. (2017). Base Nacional Comum Curricular. Brasília: MEC. Ministério da Educação. http://basenacionalcomum.mec.gov.br/abase/

Kalinke, M. A.; Mocrosky, L. \& Estephan, V. M. (2013). Matemáticos, educadores matemáticos e tecnologias: uma articulação possível. Educação Matemática Pesquisa. Revista do Programa de Estudos Pós-Graduados em Educação Matemática. XV, (2), p.359-378. https://revistas.pucsp.br/index.php/emp/article/view/13363

Lorenzato, S. (2008). Educação infantil e percepção matemática. 2 ed. Editora Autores associados.

Malheiros, B. T. (2011). Metodologia da pesquisa em educação. Editora LTC.

Mendes, I. A. (2018). Metodologias investigativas para o ensino de matemática em diversidades culturais escolares. Revista de investigação e divulgação em Educação Matemática 2 , p. 63-81. https://periodicos.ufjf.br/index.php/ridema/article/download/27377/18825

Mendes, I. A. (2009). Matemática e Investigação em sala de aula: tecendo redes cognitivas na aprendizagem. Livraria da Física.

Piaget, J. (1975). A construção do real na criança. 2. ed. Editora Zahar.

Piaget, J. \& Inhelder, B. (1993). A representação do espaço na criança. Editora Artes Médicas.

Ponte, J. P.; Brocardo, J. \& Oliveira, H. (2013). Investigações matemática na sala de aula. 3 ed. Editora Autêntica.

Ponte, J. P.; Quaresma, M.; Mata-Pereira, J. \& Branco, N. (2017). Investigações matemáticas e investigações na prática profissional. Editora Livraria da Física.

Ponte, J. P. (2005). Gestão curricular em Matemática. In GTI (Ed.), O professor e o desenvolvimento curricular (pp. 11-34). APM

Rissi, M. R. \& Franco, V. S. (2008). Topologia: uma proposta metodológica para o ensino fundamental. http://www.diaadiaeducacao.pr.gov.br 
Sampaio, J. C. V. (2010). Uma introdução à topologia geométrica: passeios de Euler, superfícies, e o teorema das quatro cores. Editora UFSCar.

Sampaio, J. C. V. (2004). Quatro cores e matemática. Universidade Federal da Bahia. II Bienal da SBEM. http://www.bienasbm.ufba.br/M35.pdf

Scratch Foundation. (2015). Our Story. https://www.scratchfoundation.org/our-story

Smole, K. C. S.; Diniz, M. I. \& Cândido, P.(2014). Figuras e Formas. 2 ed. Editora Penso.

Tojeiro; P. F. S. \&Araman, E. M. O. (2017). Uma análise nos Anais dos XI, XII e XIII EPREM em busca de trabalhos que abordam os Anos Iniciais associados ao uso de Tecnologias. In: Anais do Encontro Paranaense de Educação Matemática (EPREM) (164-176). UNIOESTE. http://www.sbemparana.com.br/eventos/index.php/EPREM/XIV_EPREM/paper/vi ew/91/164

Valente, J.A. (1993). Diferentes usos do computador na educação. Computadores $e$ Conhecimento: repensando a educação. Editora UNICAMP.

Autoras

Priscilla Frida Salles Tojeiro

Bacharel e licenciada em Análise de Sistemas e Tecnologias da Informação pela Faculdade de Tecnologia de Ourinhos - FATEC (2008), especialização em Mídias em Educação pela

Universidade de São Paulo - USP (2013), graduação em Pedagogia pela Universidade

Estadual Paulista Júlio de Mesquita Filho - UNESP (2013), Mestre em Ensino de Matemática pela Universidade Tecnológica Federal do Paraná - UTFPR, campus de Londrina-PR (2019). Atualmente é professora de educação básica - nível I da Prefeitura Municipal de Ourinhos e participa do Grupo de Estudos e Pesquisa em Inclusão Social -

GEPIS - UNESP - Marília.

E-mail: priscillatojeiro@yahoo.com.br

Eliane Maria de Oliveira Araman

Possui graduação em Licenciatura Em Ciências Habilitação Em Matemática pelo Centro de Estudos Superiores de Londrina (1994), Mestrado em Ensino de Ciências e Educação

Matemática pela Universidade Estadual de Londrina (2006) e Doutorado em Ensino de

Ciências e Educação Matemática pela Universidade Estadual de Londrina (2011). É docente do Departamento de Matemática da Universidade Tecnológica Federal do Paraná -

Campus Cornélio Procópio e do Programa de Pós-Graduação Mestrado Profissional em Ensino de Matemática (PPGMAT). E-mail: eliane.araman@gmail.com 